\title{
UPPER EXTREMITIES MUSCULOSKELETAL DISORDERS: PREVALENCE AND ASSOCIATED ERGONOMIC FACTORS IN AN ELECTRONIC ASSEMBLY FACTORY
}

\author{
SOMTHUS PULLOPDISSAKUL ${ }^{1}$, CHATCHAI EKPANYASKUL ${ }^{1}$, \\ SASITORN TAPTAGAPORN² 2 , ADUL BUNDHUKUL ${ }^{3}$, \\ and ARUNWONGSE THEPCHATRI ${ }^{4}$
}

${ }^{1}$ Srinakharinwirot University, Bangkok, Thailand

Faculty of Medicine, Department of Preventive and Social Medicine

${ }^{2}$ Thammasat University, Pathum Thani, Thailand

Faculty of Public Health

${ }^{3}$ Nopparat Rajathanee Hospital, Bangkok, Thailand

Occupational and Environmental Medicine Center

${ }^{4}$ Srinakharinwirot University, Bangkok, Thailand

Faculty of Medicine, Department of Orthopedics

\begin{abstract}
Objectives: To determine the magnitude, distribution and associated ergonomic factors of upper extremities musculoskeletal disorders (UEMSD) among workers of electronic assembly in Thailand. Material and Methods: This was a crosssectional study. 591of 853 workers in an electronic and electrical appliance assembly factory in Bangkok, Thailand, participated in this study. A self-administered questionnaire consisting of demographic data and ergonomic factors was collected from October 2010 to January 2011. Clinical examination of each worker was performed by an occupational physician. The criteria for diagnosis of UEMSD came as a result of a consensus reached by a group of orthopedists. The associated factors were analyzed using a multiple logistic regression. Results: The point prevalence of clinically diagnosed UEMSD was as follows: radial styloid tenosynovitis - 13.03\% (95\% CI: 10.31-15.75), trigger finger - 9.48\% (95\% CI: 7.11-11.84), carpal tunnel syndrome - 8.12\% (95\% CI: 5.91-10.33), lateral epicondylitis - 3.38\% (95\% CI: 1.92-4.85), and medial epicondylitis $-1.69 \%$ (95\% CI: 0.65-2.73), respectively. The adjusted odds ratio with statistical significance associated with UEMSD was as follows: high force of wrist - 1.78 (95\% CI: 1.06-2.99), awkward posture of wrist -2.37 (95\% CI: 1.28-4.37) and contact stress at wrists -1.75 (95\% CI: 1.02-3.00) to develop radial styloid tenosynovitis. For trigger finger, the ratios were awkward posture of fingers - 2.09 (95\% CI: 1.12-3.90) and contact stress on finger - 1.86 (95\% CI: 1.04-3.34). For medial epicondylitis, it was an awkward posture of using elbows - 3.14 (95\% CI: 1.10-8.95). However, this study did not find any associations between repetitive motion and any UEMSD. Conclusions: UEMSD are most commonly found in electronic assembly workers. The relevant parties should provide comprehensive ergonomic resolution for these workers.
\end{abstract}

Key words:

Repetitive strain injury, Upper extremity, Electronic assembly, Ergonomic

Received: June 21, 2012. Accepted: October 10, 2013.

Corresponding author: C. Ekpanyaskul, Department of Preventive and Social Medicine, Faculty of Medicine, Srinakharinwirot University, 114 Sukhumvit 23, Wattana, Bangkok, 10110, Thailand (e-mail: dr_chatchai@hotmail.com). 


\section{INTRODUCTION}

In the past 10 years, research related to occupational epidemiological studies around the world, including Asia, has indicated that upper extremities musculoskeletal disorders (UEMSD) caused by working conditions or working environment constitute the most common musculoskeletal disorders. Each year, more than 3 million new workers suffer from this problem, which needs to be addressed, as otherwise, it will lead to chronic symptoms and disability [1]. These, on the other hand, cause economic burdens e.g., less income due to decreasing productivity, more expenses due to hiring labor to substitute for sick workers on leave, and more money spent on medical treatment and recovery in the case of disability [2]. The costs of workrelated musculoskeletal disorders in developed and developing countries range from 0.5 to $2 \%$ of the GDP [3]. In recent years, industry around the world has been aggressively introducing new technologies and a variety of products in order to respond to the needs of the population's consumption and lifestyle. The electronic and electrical appliance industry plays a major role in the country's business and contributes to the national income. There has been a shift in this business sector from developed to developing countries such as investment in the countries of Southeast Asia. In Thailand, for example, the electronic industry employs more than 500000 workers to assemble and distribute products all over the world. Previous scientific studies have shown that this population is at a high risk of developing musculoskeletal problems. In 2008, statistics from the Workmen' Compensation Fund in Thailand identified musculoskeletal disorders as one of the top three occupational problems affecting working population. The most common problems were disorders caused by forceful work (54.93\%) and awkward posture when working (13.52\%). This problem is mainly caused by improper motion when working due to ergonomic problems in the workplace [4]. Manufacturing electrical appliances and electronic gadgets involves dealing with a number of small parts, and therefore, workers employed there risk development of UEMSD in various parts of the body. Several epidemiological studies have indicated that repetitive motion, high force, awkward posture, and contact stress are vital ergonomic factors associated with musculoskeletal disorders.

In 2010, the International Labor Organization (ILO) held a meeting to announce a new list of occupational diseases based on recommendation no. 194 (R 194), which was a revised version of the one from the last meeting in 2002. Musculoskeletal disorders of the upper extremities were cited as epicondylitis, carpal tunnel syndrome, radial styloid tendinitis, and trigger finger [5]. In Thailand, however, studies related to these diseases focus exclusively on definite clinical diagnosis, and ergonomic factors associated with them remain unexplored. Therefore, this study aimed to determine the prevalence, distribution, and associated ergonomic factors of UEMSD in workers at electronic and electrical appliance assembly factories in Thailand. This report also includes the effects of the diseases on working life, daily life and on the prevention plans of companies/organizations concerning these epidemic problems in the future.

\section{MATERIAL AND METHODS}

The study was approved by the institutional review board of Srinakharinwirot University and was conducted in compliance with the Declaration of Helsinki regarding ethical principles for medical research involving human subjects. A written informed consent was obtained from all the participants prior to the commencement of the study.

\section{Study population}

This cross-sectional study was conducted on the workers in a plant manufacturing electrical appliances and in a plant manufacturing electronic gadgets belonging to one electronic factory in Bangkok, Thailand. The study participants were workers of 3 departments of the production plants. Their working processes were as follows: 
1. Manual control department - the majority of work consists in injecting plastic by a machine controller. The work starts with the machine spraying plastic onto a mould. When the plastic starts to coagulate, the worker extends the elbow to pick up the piece from that mould. After trimming the plastic piece with scissors, the worker places the finished part in a provided box and sends it to the assembly department.

2. Assembly department - the majority of work deal with pressing by a machine controller. The machine in the work station either runs automatically or has to be operated manually. In automatic operation, the worker collects the work piece from the machine line by extending the elbow to hold it, puts it into the provided box, and submits it to the assembly department. In the case of manual work, the worker picks up a steel plate and extends the forearm to put it into the machine, and then presses the button to run the machine. Subsequently, the worker collects the completed work and places it in the box on the side.

3. Pressing department - there are 2 working processes in the pressing department. First, riveted work starts by picking up work pieces and placing them on a riveting machine. After that, the worker presses the button for drilling holes or fixing screws on the work piece. When the work is done, the worker sends the finished work to the next worker. Next, assembly work begins with picking up the work piece and laying it onto the provided table. Then, the parts of each piece are assembled using a screwdriver, soldering, and pressing with a finger. Again, when the work is done, the worker sends the finished work to the next worker.

The inclusion criteria for workers in this study considered workers who had been working continuously in the production line for more than 6 months and were not pregnant. The data was checked by the human resource department. Finally, the total sample of people eligible for this study consisted of 853 workers.

\section{Data collection}

After obtaining permission from the electronic factory, a walk-through survey was performed to observe working conditions and to collect basic and general information on the factory. Self-administered questionnaires, which were used to collect demographic data and ergonomic factors, were collected from October of 2010 to January of 2011. Participation was on a voluntary basis. A physical medical examination, which included elbows, wrists, hands, and fingers was done by an occupational physician diagnosing UEMSD in the same period as the questionnaire collection. A cervical examination was also conducted to rule out cervical problems that mimic the UEMSD in this study.

\section{Ergonomic risk factor}

Exposure to ergonomic risk factors arising from work activities was analyzed by a self-evaluation in one part of the self-administrated questionnaire. Previous studies suggested that this method was safe, cost reducing and suitable for an epidemiological study [6]. Four ergonomic dimensions were highlighted and assessed in this study [7]:

1. Repetitive motion referring to performing the same motion or series of motions continually or frequently for a period of work time.

2. High force representing excessive physical effort required to perform a task.

3. Awkward posture referring to repeated or prolonged reaching, twisting, bending, working overhead, or keeping fixed positions.

4. Contact stress occurring when a part of the upper extremity presses against a hard or sharp edge, or when the hand is used as a hammer.

The workers who answered "yes" in a given question for each body part including elbow, wrist or finger were classified as having those risk factors. The kappa coefficient of test-retest reliability in all four ergonomic factors was 1.0. The sensitivity and specificity of this tool, however, requires further evaluation. 


\section{Criteria for UEMSD diagnosis}

The diseases considered in this study were: medial epicondylitis, lateral epicondylitis, carpal tunnel syndrome, radial styloid tenosynovitis and trigger finger. Clinical diagnosis of these diseases was based on history taking and a physical examination. The criteria for UEMSD diagnosis were adapted from a previous study [8] and came from a consensus concerning criteria reached by a group of orthopedists (12 persons) with an Index of Item-Objective Congruency (IOC) score higher than 0.80 . The workers who were positive for both history factors in the previous week and the physical examination were classified as diseased, while the others, with only one positive factor of history or physical examination or no factors at all, were classified as non-diseased. The details of each UEMSD diagnostic criteria are shown in Table 1.

\section{Statistical analysis}

Statistical analysis was performed using SPSS software (version 19.0, SPSS Incorporated). The descriptive data was presented in numbers and percentages. The prevalence rate, expressed in percentage with a 95\% confidence interval (CI), was selected to report the magnitude of UEMSD problems in this study. Simple logistic regression was utilized in the univariate analysis to determine any associations between the UEMSD and each of the demographic and ergonomic risk factors. Multi-collinearity was checked and followed the procedure of Chan [9]. The multiple logistic regression adjusted for confounding factors was reported in the final model. Enter procedure was used in the statistical modelling. The appropriateness of the final model was checked using the Wald and HosmerLemeshow goodness-of-fit test. The statistical significance level was set at a $p$-value lower than $0.05(p<0.05)$. The strength association in this study was displayed by the crude and adjusted odds ratio with a 95\% CI [9].

\section{RESULTS}

Of 853 eligible production workers of this factory, 591 workers participated in the physical examination and completed the questionnaire, simultaneously yielding a participation rate of $69.3 \%$. Most workers were female, their age ranged from 18 to 30 years and all of them graduated from high school. Only 9 workers were current smokers $(1.5 \%)$ and 146 workers $(24.7 \%)$ had an abnormal Body Mass Index. Most of the participants were from the assembly departments and had worked for 1-5 years. 9.1\% had a history of upper extremity accidents. All details are presented in Table 2.

\section{Prevalence of UEMSD}

This study found that 175 workers were diagnosed with at least one UEMSD episode, yielding the point prevalence rate of $29.61 \%$ (95\% CI: 25.92-33.30). The details

Table 1. This study's criteria for diagnosing upper extremities musculoskeletal disorders (UEMSD)

\begin{tabular}{|c|c|c|}
\hline UEMSD & History in previous week & Physical examination \\
\hline Medial epicondylitis & pain at medial side of elbow & $\begin{array}{l}\text { tender to palpation at medial epicondyle or pain localized } \\
\text { to medial epicondyle when resisting wrist flexion }\end{array}$ \\
\hline Lateral epicondylitis & pain at lateral side of elbow & $\begin{array}{l}\text { tender to palpation at lateral epicondyle or pain localized } \\
\text { to lateral epicondyle when resisting wrist extension }\end{array}$ \\
\hline Carpal tunnel syndrome & $\begin{array}{l}\text { pain or numbness radiating to median } \\
\text { nerve or numbness or tingling at night }\end{array}$ & $\begin{array}{l}\text { Phalen's test positive or Tinel's sign positive or Thenar } \\
\text { muscle atrophy }\end{array}$ \\
\hline Radial styloid tenosynovitis & pain at radial side of wrist & $\begin{array}{l}\text { tender to palpation at radial styloid or Finkelstein's test } \\
\text { positive }\end{array}$ \\
\hline Trigger finger & history of catching & $\begin{array}{l}\text { tender at A1 pulley or demonstrable cathing or cannot flex } \\
\text { or extend finger }\end{array}$ \\
\hline
\end{tabular}


Table 2. The general characteristics and their prevalence rates stratified by the general characteristics of the workers who participated in this study

\begin{tabular}{|c|c|c|c|c|}
\hline \multirow[t]{2}{*}{ Characteristics } & \multicolumn{3}{|c|}{$\begin{array}{c}\text { Workers }(\mathrm{N}=591) \\
\mathrm{n}(\%)\end{array}$} & \multirow[t]{2}{*}{$\mathrm{p}$} \\
\hline & total & disease & non disease & \\
\hline Sex & & & & 0.16 \\
\hline male & $20(3.4)$ & $3(15.0)$ & $17(85.0)$ & \\
\hline female & $571(96.6)$ & $172(30.1)$ & $399(69.9)$ & \\
\hline Age group (years) & & & & 0.37 \\
\hline $18-30$ & $386(65.3)$ & $107(27.7)$ & $279(72.3)$ & \\
\hline $31-40$ & $159(26.9)$ & $52(32.7)$ & $107(67.3)$ & \\
\hline $41-50$ & $46(7.8)$ & $16(34.8)$ & $30(65.2)$ & \\
\hline Education & & & & 0.001 \\
\hline secondary school & $107(18.1)$ & $41(38.3)$ & $66(61.7)$ & \\
\hline high school & $425(71.9)$ & $112(26.4)$ & $313(73.6)$ & \\
\hline diploma & $44(7.5)$ & $12(27.3)$ & $32(72.7)$ & \\
\hline bachelor's degree / higher & $15(2.5)$ & $10(66.7)$ & $5(33.3)$ & \\
\hline Current smoking habit & & & & 0.63 \\
\hline non-smokers & $582(98.5)$ & $173(29.7)$ & $409(70.3)$ & \\
\hline smokers & $9(1.5)$ & $2(22.2)$ & $7(77.8)$ & \\
\hline Body Mass Index & & & & 0.001 \\
\hline < 18.5 (underweight) & $71(12.0)$ & $23(32.4)$ & $48(67.6)$ & \\
\hline 18.5-24.9 (normal weight) & $445(75.3)$ & $115(25.8)$ & $330(74.2)$ & \\
\hline 25.0-29.9 (overweight) & $63(10.7)$ & $29(46.1)$ & $34(53.9)$ & \\
\hline > 30 (obesity) & $12(2.0)$ & $8(66.7)$ & $4(33.3)$ & \\
\hline Department & & & & 0.45 \\
\hline pressing & $82(13.9)$ & $22(26.8)$ & $60(73.2)$ & \\
\hline assembly & $400(67.7)$ & $125(31.3)$ & $275(68.7)$ & \\
\hline manual control & $109(18.4)$ & $28(25.7)$ & $81(74.3)$ & \\
\hline Duration of employment (years) & & & & 0.29 \\
\hline $1-5$ & $370(62.6)$ & $103(27.8)$ & $267(72.2)$ & \\
\hline $6-10$ & $100(16.9)$ & $36(36.0)$ & $64(64.0)$ & \\
\hline$>10$ & $121(20.5)$ & $36(29.8)$ & $85(70.2)$ & \\
\hline Upper extremities accident history & & & & 0.75 \\
\hline no & $537(90.9)$ & $158(29.4)$ & $379(70.6)$ & \\
\hline yes & $54(9.1)$ & $17(31.5)$ & $37(68.5)$ & \\
\hline Hobby history & & & & 0.68 \\
\hline no & $567(95.9)$ & $167(29.5)$ & $400(70.5)$ & \\
\hline yes & $24(4.1)$ & $8(33.3)$ & $16(66.7)$ & \\
\hline Secondary job & & & & 0.33 \\
\hline no & $582(98.5)$ & $171(29.4)$ & $411(70.6)$ & \\
\hline yes & $9(1.5)$ & $4(44.4)$ & $5(55.6)$ & \\
\hline
\end{tabular}


of each UEMSD stratified by the department are shown in Table 3. This study revealed that radial styloid tenosynovitis was the most common UEMSD in electrical appliance and electronic gadget manufacturing workers, while the medial epicondylitis occurred with the lowest prevalence in this population. Moreover, this study found that 28 workers $(16 \%)$ from the total diagnostic workers had more than one UEMSD. The top three common dual diseases were as follows: radial styloid tenosynovitis with lateral epicondylitis, found in 7 workers (25\%); radial styloid tenosynovitis with trigger finger, found in 5 workers (17.9\%); and carpal tunnel syndrome with radial styloid tenosynovitis, found in 4 workers $(14.3 \%)$. For elbow and wrist, the most affected side of the body was the right side $(51.7 \%)$. In the case of fingers, the most commonly affected fingers were the 2nd fingers (53.6\%).

The UEMSD-diagnosed workers were frequently members of the study group with the following factors: female, older age, higher education, non-smoker, overweight/obese, working in assembly line, 6-10 years of employment, had a history of upper extremities accidents, and had a hobby or secondary job. The details of the prevalence rate stratified by each factor are also shown in Table 2 .

In the univariate analysis, the demographic factors which were associated with UEMSD and had statistical significance were: education and Body Mass Index ( $p=0.001)$.
Nevertheless, for all demographic factors, there was no associations with UEMSD in the multivariate analysis.

\section{Ergonomic factors and UEMSD}

The distribution of each ergonomic factor classified by each UEMSD is shown in Table 4. UEMSD-diagnosed workers had the proportion of poor ergonomics higher than the non-diseased workers, except for the cases of carpal tunnel syndrome and contact stress at wrist. All ergonomic factors had multicollonearity together. So, this study did not put all ergonomic factors into one model. Each ergonomic factor adjusted for gender, age, education and Body Mass Index was analyzed in each final model. For each ergonomic factor, the statistical significance adjusted odds ratio associated with UEMSD when classified according to each disease of UEMSD was as follows: high force of wrist - 1.78 (95\% CI: 1.06-2.99), awkward posture of wrist -2.37 (95\% CI: 1.28-4.36) and contact stress at wrists - 1.75 (95\% CI: 1.02-3.00) to develop radial styloid tenosynovitis. For trigger finger, the ratios were: awkward posture of fingers -2.07 (95\% CI: 1.11-3.88) and contact stress on finger -1.86 (95\% CI: 1.04-3.33). In the case of medial epicondylitis, it was awkward posture of using elbows - 3.18 (95\% CI: 1.12-9.05). However, in this study no association was found between the repetitive motion and any UEMSD (Table 5).

Table 3. Proportion and 95\% CI of UEMSD among electronic assembly workers in this study

\begin{tabular}{|c|c|c|c|c|}
\hline \multirow[b]{2}{*}{$\begin{array}{c}\text { Upper extremities } \\
\text { musculoskeletal disorders }\end{array}$} & \multicolumn{4}{|c|}{ Prevalence rate per 100 workers $(95 \% \mathrm{CI})$} \\
\hline & $\begin{array}{c}\text { total } \\
(\mathrm{N}=591)\end{array}$ & $\begin{array}{l}\text { pasting department } \\
\qquad(\mathrm{N}=109)\end{array}$ & $\begin{array}{l}\text { assembly department } \\
\qquad(\mathrm{N}=400)\end{array}$ & $\begin{array}{c}\text { manual control } \\
\text { department } \\
(\mathrm{N}=82)\end{array}$ \\
\hline Medial epicondylitis & $1.69(0.65-2.73)$ & $4.59(0.66-8.52)$ & $2.75(1.15-4.35)$ & $4.88(0.22-9.54)$ \\
\hline Lateral epicondylitis & $3.38(1.92-4.85)$ & $0(0-3)^{*}$ & $1.75(0.46-3.04)$ & $3.66(0.04-7.72)$ \\
\hline Carpal tunnel syndrome & $8.12(5.91-10.33)$ & $7.34(2.44-12.24)$ & $8.25(5.55-10.95)$ & $8.54(2.49-14.59)$ \\
\hline Radial styloid tenosynovitis & $13.03(10.31-15.75)$ & $9.17(3.75-14.59)$ & $15.25(11.73-18.77)$ & $7.32(1.68-12.96)$ \\
\hline Trigger finger & $9.48(7.11-11.84)$ & $11.93(5.84-18.02)$ & $9.25(6.41-12.09)$ & $7.32(1.68-12.96)$ \\
\hline
\end{tabular}

CI - confidence interval.

* Based on Poisson approximation for binomial distribution. 

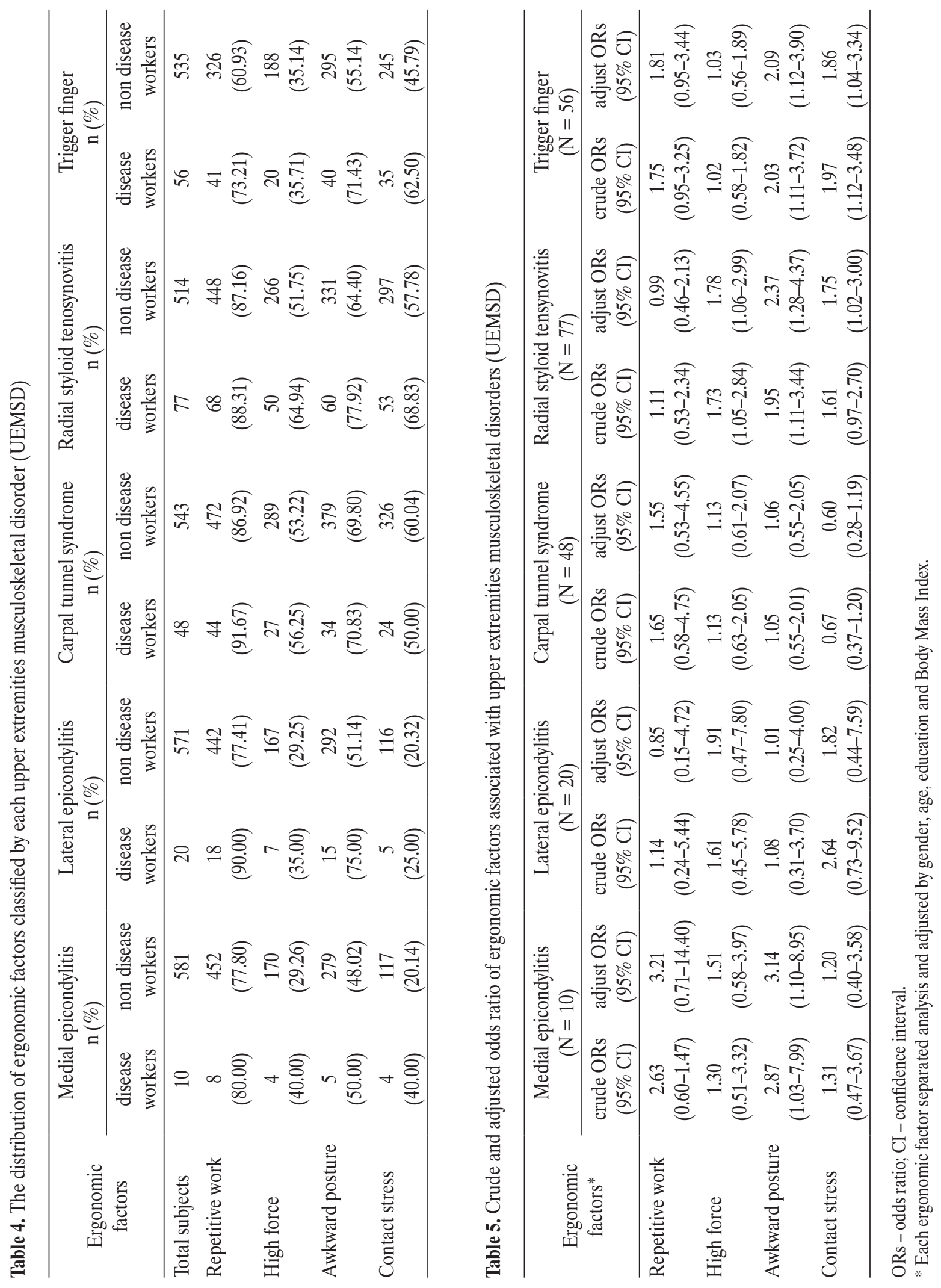


\section{Severity of UEMSD}

It was reported that most of the affected workers in this study were in the subclinical or mild state. Of all the diagnosed 175 workers, 1 out of 5 needed treatment, 18 workers $(10.3 \%)$ took some medications from a pharmacy, 13 workers $(7.4 \%)$ visited a physician in a hospital, and 5 workers $(2.9 \%)$ had steroid injection. Some workers reported that their daily life was affected by the disease, e.g., 19 workers $(10.9 \%)$ had difficulty in doing some housework. It also affected work productivity - 26 workers (14.9\%) had work difficulty or work discomfort, while 3 workers $(1.7 \%)$ reported work piece damage.

\section{DISCUSSION}

This research was an epidemiological study of UEMSD that investigated diseases of the elbow, wrist, and finger by clinical diagnosis and its associated ergonomic factors. Most of the workers from the electronic factory were younger females, 18-30 years old, and working in an assembly department. As the working processes mostly involved the use of upper extremities, particularly the wrist and hand, this population was vulnerable to developing upper extremities musculoskeletal problems.

The point prevalence of clinically diagnosed UEMSD found in this study was, from the highest to the lowest percentage: radial styloid tenosynovitis or de Quervain's tenosynovitis, trigger finger, carpal tunnel syndrome, lateral epicondylitis, and medial epicondylitis, respectively. In this study, tendon inflammations and related conditions such as tendonitis and tenosynovitis were found as more common UEMSD in the manufacturing setting than nerve entrapment neuropathies. The result was in accordance with the findings of other epidemiological studies [10-13], but contrasted with labour statistics [14] or surveillance systems [15]. The reason is that the cases from the active findings in this research included all stages of the diseases starting with inflammation process and finishing with the disability stage while most of the cases from workers' compensation data and surveillance were in clinical stage or chronic one. The magnitude of UEMSD was also higher than in a service setting such as computer office work $[16,17]$. The pattern of the prevalence rate of UEMSD has not increased in comparison to the past decade in the industrial countries [18]. However, due to the differences in the studies' worker population, work characteristics, methodology, as well as assessment, a direct comparison with other studies is difficult and should be done with caution.

The current understanding of work-related musculoskeletal disorders, occupational biomechanics, play an important role in the etiology [19]. The study findings revealed that high force, awkward posture and contact stress were associated with UEMSD. For radial styloid tenosynovitis, high force of the wrist was associated with this disease. The high force often caused direct injury to the tendon with possible damage to it. When the high force is combined with other ergonomic factors found in some work processes of this study, such as awkward posture, a higher force acts on the tendon of the wrist. The awkward position in this study during some working processes, e.g. when using devices such as a screwdriver or scissors, frequently caused wrist twist. Twisting work posture often with applied force can cause radial tendon injury to the wrist and is compatible with the mechanism of radial styloid tenosynovitis pathogenesis [20]. Contact stress at the wrists associated with radial styloid tenosynovitis has never been reported in previous studies [19]. When considering a worker who had contact stress risk factors, it was found that half of them performed tasks which involved pressing a work piece with a thumb. The act of pressing transmits the force to the radial styloid, causing internal strain between the radial styloid process and the tendon of the abductor pollicis longus and extensor policis brevis. Therefore, this may be the underlying cause of this disease in the electronic assembly workers.

The associated factors of trigger finger included an awkward posture and contact stress of using the finger. The 
continuous use of the hand at work can cause a cumulative irritation of the sheath by the forceful back and gliding of the tendon during repetitive movements [20]. The relationship between the trigger finger with the awkward posture in this study may occur when bent fingers press the machinery all the time; the flexor muscle of the finger tendon is pulled through the A1 pulley, resulting in pressure on the A1 pulley. The working process as in the continuous use of fingers to press on pieces of work, causes friction between the tendon and A1 pulley. This results in an increased inflammation and causes trigger finger. Contact stress on the finger was mostly found in the participants working in the pressing department. With the workers who were required to press a button to run the machine, the area of the A1 pulley was pressed all the time.

For medial epicondylitis, only awkward posture of using the elbow was associated with an ergonomic factor. In this case, the cause for the problem may be that the working process required the workers to raise the arm during work and hold it in that position at all times. In addition, the absence of an armrest to relieve the fatigue symptoms may also be a cause of the epicondylitis.

However, in this study repetitive work was found not to be associated with the occurrence of musculoskeletal disorders when compared to previous studies [21-23]. The reason for this discrepancy may be that assembly workers in the electrical and electronic appliance factories have control over their operating time. As work achievement is determined by the number of pieces of work produced per day, workers can slow down the pace when the symptoms and fatigue arise. Nevertheless, the assessment of self-evaluation on repetitive work was difficult to perform. For demographic data, education and Body Mass Index were the two factors which turned significant in the univariate analysis. Majority of the workers with higher education have mental occupational tasks and psychosocial problems. It may be a risk of UEMSD. Obesity may have a profound effect on the soft tissue structure. This effect has several pathophysiologic mechanisms and causes UEMSD [24]. Unfortunately, both factors failed to show an association in the multivariate analysis. Previous systematic review shows that psychosocial factors can aggravate UEMSD. However, this study also did not find any psychosocial factors significantly associated with UEMSD (data not shown).

The vital points addressed in this study were:

1. The prevalence of UEMSD in this group of workers was higher than in the general population $[25,26]$. Many considered ergonomic problems could be the primary cause, and so it was indicated that the UEMSD may be related to work and thus preventable.

2. This study findings show evidence that ergonomics plays an important role in developing UEMSD, and UEMSD may have an adverse effect on the work and daily life as well as cause economic loss such as the cost of treatment and productivity loss. The factory should address this problem before it becomes aggravating.

A valuable point of this research was the final report on the diagnosis of the diseases, and not the evaluation of pain or symptoms. Many epidemiological studies of upper extremity musculoskeletal problems in the workplace either did not include or did not find the diseases among their health outcomes. In this study, the outcome was diagnosed by an occupational physician basing on the history and clinical diagnosis, not merely on the subjective symptoms. However, the lack of confirmation of the diagnosis with the electromyography (EMG) or nerve conduction velocity (NCV) constitutes one of the limitations of the study.

Also bias may have occurred in this study. Disease misclassification could not be excluded. The worker who had only positive history or had sub-clinical disease was classified as non-diseased. Nevertheless, this study found less than $2 \%$ of that category in this population. The underestimation through the outcome measurement of each disease in this study was another limitation. The next limitation was the response rate. Workers who had musculoskeletal problems may not have participated in the study in order 
to avoid answering the questionnaire and undergoing the physical examination. Therefore, a non-response bias is unavoidable and may have affected the true prevalence of the problem in this study. Information on ergonomic factors, including information dependence on the subjective determination of a worker, may result in information bias. The cross-sectional study design would allow establishing the association between UEMSD and ergonomic risk factors but not to draw conclusions concerning the temporality of their relationship. Therefore, further study should focus on prevention of these problems and improving the design or exposure and outcome measurement to reduce potential bias.

\section{CONCLUSIONS}

UEMSD is a common musculoskeletal problem among the workforce of a developing countries. Radial styloid tenosynovitis had a high prevalence in the electronic assembly industry. The ergonomic factors associated with UEMSD included awkward posture, high force exertion, and contact stress. This problem induces many adverse effects on the workers as well as on the workplace. As a primary prevention of the problem, workers should be provided with comprehensive ergonomic solutions such as improving the work task and modifying work practices or work stations so as to reduce UEMSD.

\section{REFERENCES}

1. Leigh J, Macaskill P, Kuosma E, Mandryk J. Global burden of disease and injury due to occupational factors. Epidemiology. 1999;10(5):626-31, http://dx.doi.org/10.1097/00001648199909000-00032.

2. Jones JR, Huxtable CS, Hodgson JT. Self-reported workrelated illness in 2003/2004: Results from the Labour force survey. Sudbury, Suffolk: HSE Books; 2005. p. 450.

3. Piedrahita H. Costs of work-related musculoskeletal disorders (MSDs) in developing countries: Colombia case. Int J Occup Saf Ergon. 2006;12(4):379-86.
4. Social Security Office, Ministry of Labor. [Social Security Statistics]. Bangkok: Social Security Office; 2009. p. 168. Thai.

5. International Labour Organization. Recommentation 194 List of occupational diseases recommendation (revise 2010). Geneva: ILO; 2010. p. 8.

6. David GC. Ergonomic methods for assessing exposure to risk factors for work-related musculoskeletal disorders. Occup Med (Lond). 2005;55(3):190-9, http://dx.doi.org/10.1093/ occmed/kqi082.

7. Occupational Safety and Health, Department of Labour. Ergonomics for the prevention of musculoskeletal disorders. Guideline for retail grocery store. Washington DC: Department of Labour; 2004. p. 28.

8. Sluiter JK, Rest KM, Frings-Dresen MHW. Criteria document for evaluating the work-relatedness of upper-extremity musculoskeletal disorders. Scand J Work Environ Health. 2001;27(Suppl 1):1-102, http://dx.doi.org/10.5271/ sjweh.637.

9. Chan YH. Biostatistics 202: Logistic regression analysis. Singapore Med J. 2004;45(4):149-53.

10. Nicoletti S, Carino M, Di Leone G, Trani G, Carella F, Rubino G, et al. Prevalence of upper limb work - related musculoskeletal disorders (UL-WMSDs) in workers of the upholstered furniture industry. Med Lav. 2008;99(4):271-80.

11. Forde MS, Punnett L, Wegman DH. Prevalence of musculoskeletal disorders in union ironworkers. J Occup Environ Hyg. 2005;2(4):203-12, http://dx.doi. org/10.1080/15459620590929635.

12. Treaster DE, Burr D. Gender differences in prevalence of upper extremity musculoskeletal disorders. Ergonomics. 2004;47(5):495-526, http://dx.doi.org/10.1080/001401 30310001638171.

13. Sukenik S, Flusser D, Abushakra M. Work related musculoskeletal disorders of the upper extremity. Harefuah. 2007;146(2):120-5, 165.

14. U.S. Department of Labour and Bureau of Labour and Statistics. Occupational injuries and illnesses: counts, rates, and 
characteristics. Bulletin 2592. Washington, DC: U.S. Department of Labour; 2005 [cited 2010 May 29]. Available from URL: http://www.bls.gov/iif/oshbulletin2005.htm.

15. Roquelaure Y, Ha C, Leclerc A, Touranchet A, Sauteron M, Melchior M, et al. Epidemiologic surveillance of upperextremity musculoskeletal disorders in the working population. Arthritis Rheum. 2006;55(5):765-78, http://dx.doi. org/10.1002/art.22222.

16. Waersted M, Hanvold TN, Veiersted KB. Computer work and musculoskeletal disorders of the neck and upper extremity: A systematic review. BMC Musculoskelet Disord. 2010;11:79, http://dx.doi.org/10.1186/1471-2474-11-79.

17. Pascarelli EF, Hsu YP. Understanding work-related upper extremity disorders: clinical findings in 485 computer users, musicians, and others. J Occup Rehabil. 2001;11(1):1-21, http://dx.doi.org/10.1023/A:1016647923501.

18. Huisstede BM, Bierma-Zeinstra SM, Koes BW, Verhaar JA. Incidence and prevalence of upper-extremity musculoskeletal disorders. A systematic appraisal of the literature. BMC Musculoskelet Disord. 2006;7:7, http://dx.doi. org/10.1186/1471-2474-7-7.

19. Halpern M. Chapter 57 Ergonomics and occupational biomechanics. In: Willium N, Rom SBM, editors. Environmental and Occupational Medicine. 4th ed. Philadelphia: Lippincort William \& Wikins; 2007. p. 908.

20. Barr AE, Barbe MF, Clark BD. Work-related musculoskeletal disorders of the hand and wrist: epidemiology, pathophysiology and sensorimotor changes. J Orthop Sports
Phys Ther. 2004;34(10):610-27, http://dx.doi.org/10.2519/ jospt.2004.34.10.610.

21. Roquelaure Y, Ha C, Rouillon C, Fouqet N, Leclerc A, Descatha A, et al. Risk factors for upper-extremity musculoskeletal disorders in the working population. Arthritis Rheum. 2009;61(10):1425-34, http://dx.doi.org/10.1002/ art.24740.

22. Descatha A, Roquelaure Y, Chastang JF, Evanoff B, Cyr D, Leclerc A. Description of outcomes of upper - extremity musculoskeletal disorders in workers highly exposed to repetitive work. J Hand Surg Am. 2009;34(5):890-5, http:// dx.doi.org/10.1016/j.jhsa.2009.02.012.

23. Punnett L, Wegman DH. Work-related musculoskeletal disorders: The epidemiologic evidence and the debate. J Electromyogr Kinesiol. 2004;14(1):13-23, http://dx.doi. org/10.1016/j.jelekin.2003.09.015.

24. Wearing SC, Hennig EM, Byrne NM, Steele JR, Hills AP. Musculoskeletal disorders associated with obesity: A biomechanical perspective. Obes Rev. 2006;7(3):239-50, http:// dx.doi.org/10.1111/j.1467-789X.2006.00251.x.

25. Atroshi I, Gummesson C, Johnsson R, Ornstein E, Ranstam J, Rosén I. Prevalence of carpal tunnel syndrome in a general population. JAMA. 1999;282(2):153-8, http:// dx.doi.org/10.1001/jama.282.2.153.

26. Shiri R, Viikari-Juntura E. Lateral and medial epicondylitis: role of occupational factors. Best Pract Res Clin Rheumatol. 2011;25(1):43-57, http://dx.doi.org/10.1016/j. berh.2011.01.013.

This work is available in Open Access model and licensed under a Creative Commons Attribution-NonCommercial 3.0 Poland License - http://creativecommons.org/ licenses/by-nc/3.0/pl/deed.en. 